\title{
On the value of decorative vocabulary in the oil painting arts
}

\author{
Wen Peng ${ }^{1, a}$ \\ ${ }^{1}$ College of Fine Arts, China West Normal University, Sichuan,Nanchong, China 637009 \\ alaowen-001@163.com
}

Keywords: Decorative vocabulary, Oil painting arts, Value

Abstract. The decorative vocabulary is a huge treasure trove of artistic development history of human arts. With it's self-contained art form and easy-going art integration, it is combined with oil painting easily and has achieved impressive results. Discussing the cultural value, the aesthetic value and the value of innovation about the decorative vocabulary in oil paintings, this paper affirms the value of the decorative vocabulary in oil paintings from aesthetic point.

\section{Introduction}

The decoration plays an important role in arts and human's daily lives. The decorative expression was born with the development of oil painting arts. From The portrait of Giovanni Arno couple which was regarded as the first oil painting to various oil woks in today, the decorative vocabulary is important for the oil painting arts. Adding the decorative vocabulary into the oil painting arts, not only balances and riches the paintings' effects, but also increases the paintings' literary and historical sense and deepens the paintings' creation of the artistic conception. The reasonable use of decorative elements can activate the entire work. Analyzing on the current oil works, the decorative vocabulary expresses the cultural value, the aesthetic value and the value of innovation, which riches the constructional relation of works and enhances the he aesthetic value of oil painting arts.

\section{The establishment of model}

\section{The cultural value of decorative vocabulary in oil painting arts}

As a special product of ideology, the arts uses a variety of objects to explain the creators' understanding of the world and the nature. "Nature is the object of human activity, it provides a realistic basis for all human cognitive activity and physicochemical activities; culture is the sum of all the material products and the spiritual products of human creativity, which includes all manner of human activity and products. It is the organic whole which is composed of elements of physical, mental, language and symbols, norms and social organizations."[1]. In this organic whole, the decorative vocabulary has a special cultural quality. At the same time, "it is not entirely the part of the culture, but is equal to the culture. The arts always expresses the soul of culture-cultural psychology by its own special form, acting as a consciousness that the culture is consistent with the structure. No matter the arts chooses what forms, appears by what aesthetic styles, the cultural awareness is the same. So the certain arts must be the consciously or unconsciously outward of the structure of cultural psychology which is constructed by the certain cosmic consciousness"[2].

"Raymond Williams said that the culture at least had three usages: first, the culture was the development process of the sum of the wisdom, spirit and aesthetics; secondly, the culture was the certain way of life whether it be a nation, a period or a group; finally, the culture was the achievement and practice of the wisdom and artistic activity." "The production of decoration is based on the development of human civilization and culture, which is the cultural product and the cultural existence." [3]. From this level, the decorative vocabulary has the cultural forms,characteristics and significance. Furthermore, the decorative vocabulary is a popular art form. It emphases on the will of the mass in an era, permeates in our daily lives and all kinds of behavior, and integrates the unique rule of decoration into many art forms. Then, the decorative vocabulary reflects a distinct aesthetic characteristics of the national culture, highlights a heavy human feeling. For a long time, the oil painting 
arts is considered as a art reproduction, and also plays a "story-talking" role. In fact, with the development of oil painting arts, it was given a lot of cultural characteristics, especially in China. Since oil paintings' nationalization and localization, this cultural characteristics becomes more obviously. And the direct involvement of decorative vocabulary is link to this closely. The application mode of decorative vocabulary in oil painting arts makes us recognize the cultural character and significance of oil paintings, and reveals the nature of the objects and the law of human culture, which are reflected by oil paintings. Because of its unique cultural spirit, the decorative vocabulary gives impetus to the change of the cultural traits, and makes a new interpretation about the development of oil painting arts.

Culture is seen as the whole of one social lifestyle. As a result, the different styles which were formed between different countries, different regions and different ethnic groups, reflect the cultural characteristics and artistic personality of their own national and regional culture. This unique cultural characteristics and artistic personality using in oil paintings, must make the oil painting language exhibit the obvious regional characteristics and cultural features.

All along, the painters are trying to differ from the others' in the creation of oil paintings. The different styles caused by the differences of the regions and the cultures, are regarded as the magic weapons by the painters. Among Xinjiang school, Lijiang school and Lingnan school, the regional cultures brought the cultural plot of region to the creation of the oil paintings. The painters have infiltrated a unique cultural spirit in painting works, so that it has a significant cultural value. The decorative vocabulary that can be used as a unique cultural symbol adds in oil painting arts, in order to help the oil painting to achieve their cultural values and cultural identity.

\section{The aesthetic value of decorative vocabulary in oil painting arts}

Aesthetics is a very important part of many functions in the oil painting arts. Adding decorative vocabulary into it, can improve aesthetic interest of oil painting arts. With the development of modern science, technology, culture, economy and the awareness of popular aesthetics, the oil painting arts contacts with the public closely. Due to the growth of the people's understanding about the works and the diversify of the oil painting arts, it is important for transferring beauty, enriching people's daily lives and improving the environment of people's living, the requirement of the public about oil painting arts is getting higher and higher.

The varied and flexible features of the decorative vocabulary are enriching the expressions of the oil paintings about the beauty. The oil paintings with the decorative element use the intuitive way to communicate with people. Thus, they can reflect the social aesthetic idea and the condition of material and cultural living immediately, meet people's spiritual needs easily and lead people into a higher aesthetic realm. At the same time, they can explain the painters' own spiritual concept and the spirit of the times. With the improvement of the concept of arts, the functions of traditional oil paintings are changing which are no longer simply to stay in the conventional performance such as narration. The inclusion of the decorative vocabulary in oil painting arts makes it create atmosphere and mood easily, landscape the works on the point of aesthetic that it can emphasize the theme. The abstract symbols and graphics in decorative vocabulary having a certain visual impact, often let the audience think consciously while enjoying the works. Thereby, it can raise their aesthetic ability.

Differing from the traditional acceptance, the audiences have their own ideas on the putting environment of oil painting arts and the requirements of the pictures about environment. They will submit their comments or suggestions at the same time appreciating paintings. In this interactive session, the oil painting arts realizes the civilization and popularization of arts. The easiest part of the public adapting to the oil paintings is the oil painting artists most easy to do it. And it is also a good choice about using the decorative vocabulary reasonably.

\section{The beauty of the form of the decorative vocabulary}

The decorative vocabulary also can exist independently in the works. It in shape, color, form has a separate beauty of the form. "Klimt thought that some individual elements of the decorative vocabulary not only respond to the pictures, but also set up separately and abstractly." [4]. In these, some decorative elements have already owned their unique meanings and formed the distinctive decorative vocabulary. And then, it is reproduced through the artists' effective organization, which can present a 
new picture of semantics under maintaining independent beauty of the form and language expression. As The portrait of Giovanni Arno couple mentioned before, the bronze mirrors, the chandeliers, the beds have not only their own form of beauty, but also certain decorative meaning. These express collectively the work's theme-the new couple's love and the family harmony.

\section{The beauty of the artistic conception of the decorative vocabulary}

The artists have been pursuing to create a profound artistic conception which reflects in the artists' ability on appreciation and creation about beauty.

The artistic conception is the essence of Chinese arts, and it is also the aesthetic core of Chinese arts. As the forms of painting, many decorative elements are refined and generalized by the artists. So they have certain characteristics, such that the patterns of dragon, phoenix and the colors of yellow, red have the obvious symbolic meaning. These elements used in the works make the people speculate on the inherent meaning of the picture and the audiences appreciate the artistic conception easily which is created by the painters. Judging from that Cezanne was pursuit in the geometrics of the images while abandoning the tedious details and Matisse finished the oil works by using the flat colors of decoration and the combination of lines, the simple combinations of points, lines and surface made us recognize the importance of the construction of artistic conception.

Wu Guanzhong, who was the expert of creating the beauty of the artistic conception, often extracted the elements of creation from simple residential in Jiangnan. The white walls and black tiles in his pen were given a strong visual impact and imagination. The Qiu Jin former residence, completed in 2002, was the representative of the simple but far-reaching conception works. This picture which is length $140 \mathrm{~cm}$, height $70 \mathrm{~cm}$, is composed of the large surface area of black, white, gray plus a large number of points and lines. A few swallows perching on the fine wire outside the wall are consistent with the concise wall, which forms the contrast and the balance between tight and loose. The contradiction contrast between the swallows' vitality and the wall's silence and the ingenious combination of the figurative images and the abstract images, highlights the tragic atmosphere strongly and leads the viewers' infinite reveries.

\section{The decorative vocabulary helps us to recognize the aesthetic value of oil arts}

The spring of 1985, the Chinese Academy of Arts and the Institute of Anhui Artists Association launched "Jing County Uprising" of chinese oil painters. The theme of this conference was to discuss the problem about the arts' nature and function, no longer dwell on the old question about the relation between the content and the form. After that, the symbolism is widely used as a major feature in the oil paintings in new era. And the painters try to use symbolism and suggestion as the main means of expression, that somehow embodied in the image depiction imply and express with this image corresponding inner feelings and ideas[5].

"Beauty is not abstract. The inner essence of things must be directly reflected in the external phenomenon and emerged through a certain form or image. So it is likely to become beautiful things"[6]. Most people appreciate the art works by sharing their eyes on the specific images which they are familiar with and can be perceived. Since the decorative vocabulary in the art of oil painting is often expressed as a prominent, bright, vivid and precise image, it allows viewers to find a familiar feeling in the picture quickly, and then touch the entire screen, in order to help the audience get the cognition of the pictures' essence, content and the others. Therefore, adding the decorative vocabulary into oil arts helps the audience to recognize the aesthetic value of the oil paintings. For some viewers, looking for "implication" of the works is a short cut to understand and appreciate the paintings.

\section{The value of innovation of decorative vocabulary in oil painting arts}

The essence of the decorative vocabulary is similar with the modern arts. The shape, texture and color of decorative language combining with the expression of oil arts can give the new inspiration to the creators, thus injecting new impetus to the creation of oil painting.

One of the localization characteristics of modern oil paintings in china is that the artists' interest in traditional cultural resources is increasing, especially those who think their audience would be foreigners. These artists tend to choose general image of chinese ancient culture, and try to revitalize 
these ancient cultural image and get new semantic interpretation. Thus it can show a new, unique aesthetic implication and realize the new value of decoration vocabulary.

Gu Liming, professor of China Academy of Art, found a way to get contemporary visual involved with the local culture in order to achieve the conversion of his own words by learning from the Chinese traditional cultural forms such as Chu and other clothing and folk woodcut. Wang Huaiqing focused on the recycling of ancient furniture form and achieved new semantic screens through the abstraction of southern residential structure. HongLing found the source of individual creation from the traditional culture. Wang Yuping formed his own fish by learning from the others. The artists' interests in the art of calligraphy have also greatly increased. They try to explore constantly by treating calligraphy as a new form of decorative vocabulary. For example, Qi Haiping, Tianjin painters, added the Chinese calligraphy into his oil painting creations, using the inherent rhythm of calligraphy to decorate the paintings' picture .Cao Jigang, implemented the request of chinese paintings to various stages of landscape creation. In all, these artists would use the traditional resources as an element of decoration and they had made gratifying achievements through rational integration [7].

The painters' interest in traditional cultural resources is a major feature of the chinese painting in the new century which is different from the policy guidance or social needs departure in the past. These traditional sources of oil painting play important role in promoting the development of oil arts, explaining the creationary value of the decorative vocabulary in oil art.

\section{Conclusion}

The decorative vocabulary is a huge treasure trove of artistic development in the history of mankind. Because of it's self-contained art form and easy-going art integration, it seems to combine with oil paintings easily and then has achieved impressive results. Adding the decorative vocabulary into oil paintings, not only learn the decorative colors, decorative molding, decorative patterning and decorative techniques, but also try to form a main line of the public aesthetic taste, which to convey aesthetic ideal, gather personal feelings, show deep thought and creative consciousness beyond individual or group and even society. The decorative vocabulary is developing continuously in oil arts, which resonates with the oil arts as a unique art form, so that It not only promotes and realizes the value of oil arts from the culture, aesthetics and innovation, and create the harmonious artistic expression of the pictures- keeping a delicate balance between different levels and materials that is the painting ideas of Secession master Klimt, but also is the pursuit of many chinese oil painting artists in current era.

\section{References}

[1] X.M.Tang: Decorative cultural Outline (Chongqing university press, Chongqing, 2009)

[2] X. Feng: Cultural Spirit of Chinese and Western Art (Shanghai painting press, Shanghai, 1993).

[3] J. Hang, J. He, L.Q. Qin: Pine bamboo plum·Chinese Traditional Graphics and Modern Visual Design (Shangdong Pictorial press, Jinan, 2005)

[4] Ivan - Stephen Stefano, J.G. Cao translated: Gustav Klimt - Art Nouveau master (Jining art press, Changchun, 2010)

[5] Refer to the oil painting seminar in 1995, also called Huangshan meeting.

[6] H.J. Wang, B.L. Yuan: Art Introduction (Higher education press, Beijing, 1994)

[7] Z.T. Shui, .Art 60 Years in China 1949-1979. Art, 2009.11, page 36. 